\title{
Youth, Social Cohesion and Digital Life: From Risk and Resilience to a Global Digital
}

\section{Citizenship Approach}

\section{$\underline{\text { Introduction }}$}

Three interrelated megatrends are often predicted to significantly impact youth over the coming 20 years: cultural diversity, digital life and mental health and wellbeing (VicHealth and CSIRO 2015: 5). These challenges have been addressed in both academic literature and policy- and programme-focused research, primarily through the frames of social cohesion and cyber-safety and the identification of risk and resilience factors. However, a siloed and individualising approach has dominated, such that research and policy and programme formulation has focused on either i) the challenges of diversity for social cohesion in the 'offline' world, particularly experiences of those identified as culturally and linguistically diverse (CALD) youth, and associated risk and protective factors and sources of resilience; or ii) digital risks, protective factors and impacts on mental health and wellbeing for mainstream youth, in a cyber-safety context (Office of the eSafety Commissioner, 2019). Policy and programme makers are increasingly urged to overcome this division to better address challenges of living in an ever-more interconnected and culturally complex world, and especially to empower 'a new generation of digital citizens at the global level... to support cohesive societies' (UNESCO, 2015:1). Our paper is intended as a contribution towards bridging the gap between social cohesion and the digital in youth research and policy agendas, and offers a more structurally-oriented conceptual approach than has framed much of the debate to date. Moving beyond the dominant focus on the psychosocial, we propose a sociologicallyinformed, global digital citizenship framework for theorising and analysing social cohesion in relation to young people's digital practices as a foundation for this agenda.

Here we critically explore some of the key research that addresses issues of social cohesion and 
digital life and practices for youth in order to understand how these domains can be better integrated, and to propose a new framework of global digital citizenship. We examine Australian and international youth scholarship and policy- and programme-focused research that deals with but does not always connect social cohesion and digital sociality and practice. We argue for a more integrative and critical approach founded in citizenship principles that moves beyond an emphasis on challenges, opportunities and interventions at the level of the psychosocial.

We begin by discussing the results of our review of academic and grey literature on youth, social cohesion, and digital practices, noting that these issues tend to fall into two separate bodies of work. First, we investigate how the concept of social cohesion has been addressed, ascertaining the dominance of a risk/protection framework, and a focus on 'offline' domains of those positioned as 'CALD' youth ${ }^{1}$. We next turn to the research on youth digital practices and lives, and again identify a tendency to frame issues around risks and protections, especially regarding wellbeing and social inclusion. We then outline a more integrated global digital citizenship approach that accounts for and can build upon the everyday civic and political processes at work in young people's engagement with the digital.

\section{$\underline{\text { Youth and Social Cohesion: The Frame of Risks and Protections }}$}

Social cohesion is a longstanding concept in academic work, and a more recent one in the policy

\footnotetext{
${ }^{1}$ We acknowledge that although this term is frequently used in the policy literature to broadly identify "racial, ethnic and religious minorities in Australia who are migrants or descendants of migrants" (Caluya, Bororica \& Yue 2018 ) that, like other similar terms, (NESB youth, multicultural youth) it has been problematized as a frame which subtly racialises and 'others' minority cultural, racial and ethnic groupings, setting them apart from white, Anglo or European background youth, and marking them as being in need of different modes of government (Cuervo \& Miranda 2019). We acknowledge the problematic associations of the term, but use it in this article where relevant to challenge another tendency in the literature, which is to collapse all young people into the homogenous category of 'youth' which closes down possibilities to critically interrogate how expressions of racism and marginalisation differentially impact youth populations. We will also use terms minoritised and multicultural youth where appropriate.
} 
context. It is associated with shared values, a common purpose in society, and strong sense of belonging (Castles, 1999: 37; Markus, 2015: 12). Markus and Kirpitchenko (2007: 21) detail the rise of the social cohesion framework in Canadian, Australian, UK, European and international policy throughout and beyond the 1990s as a response to mass migration and globalisation, with cultural diversity often seen as a challenge to harmony and shared identity in a society. From a communitarian perspective, upon which some consensus frameworks of social cohesion are based, cultural difference may itself be perceived as divisive because it militates against homogeneity (Delanty 2010:70). From a more critical social cohesion perspective, a sense of belonging together and shared purpose can be more difficult to achieve when the legitimacy of some of the community's members is challenged and social inclusion is at risk. From this view, negotiation, dialogue and engagement (rather than consensus and shared values) are considered key to the ongoing process of cohesion and active citizenship by all in a culturally diverse society.

Social cohesion has become a prominent issue in Australia owing to its increasingly culturally diverse population and long history of migration and multicultural policies. Australia is frequently regarded as a successful multicultural society according to social cohesion measures. For example, surveys conducted since 2007 establish that Australia is a stable and highly cohesive society, and that this cohesion is longstanding (Markus, 2015). Further, since 1980, Australia has also consistently scored higher than any other rated nation on the Multiculturalism Policy Index (Banting and Kymlicka, 2013). However, key factors that threaten to disrupt social cohesion are frequently identified, such as limited intercultural contact, reduced support and capacity for culture maintenance, racism, and lack of promotion of pluralism (see for example Dandy and PePua, 2013).

An interest in young people's experience of and role in social cohesion has grown in recent times, especially amidst concerns about settlement and integration of young migrants and refugees, and 
the rising influence of forms of violent extremism and terrorism, including white violent nationalism and extremism (Siapera \& Zhou 2018, Vergani 2014). Social cohesion is seen as particularly relevant for the current generation of Australian youth, who are growing up amid the normalisation of diversity. Around $49 \%$ of the Australian population is born overseas or has one parent born overseas (Australian Bureau of Statistics 2017a), and population growth continues to be driven primarily by overseas migration (Australian Bureau of Statistics 2017b). 25\% of young people aged 12-24 are identified as being from a 'CALD' background (Hugo et al. 2014). Recent research has been particularly concerned with understanding the challenges for young people regarding social cohesion in a diverse society. This is commonly undertaken through a psychosocial approach that aims to identify the risks and protective factors for social cohesion amongst ' CALD' youth that may affect their social belonging, sense of inclusion and capacity for full participation.

Some key causes of disadvantage and significant risks to social cohesion are identified as racism, discrimination and bias (Liddy, 2011; Dandy and Pe-Pua 2013: 131), leading to a loss of a sense of social cohesion, local belonging and poor mental health (Blades-Hamilton 2015; Mansouri and Kamp 2007). For youth who may be grappling both with negative social experiences, such as prejudice, and the psychological and social challenges of migration and acculturation, these stresses are often seen to result in mental health problems, including depressive and anxiety symptoms, post- traumatic stress disorder, sleep and concentration issues, psychosomatic disorders, behavioural and learning difficulties and increased risk of suicide (Mission Australia and Black Dog Institute 2015; VicHealth and CSIRO 2015; Colucci et al. 2014; Francis and Cornfoot, 2007:30). Health risk factors are also linked to psychosocial issues such as young people's cultural values and beliefs, and interpersonal communication skills (Mitchelson et al, 2010), creating a feedback loop between mental health and social cohesion. Social disadvantage and exclusion are related to poor mental health, which in turn militates against capacity for social and civic belonging 
and thus threatens social cohesion.

Other factors that pose a risk to social cohesion are lack of educational opportunities and labour market marginalization (Mansouri and Kamp 2007; McMichael et al. 2015), often related to psychosocial issues of participation and social networks (see Blades-Hamilton 2014: 27). Newly arrived and refugee-background youth are also identified as encountering other barriers that present risk factors for social cohesion, such as difficulties in transitioning to mainstream schools, dealing with family stress associated with settlement and relatives left behind, and sexual/reproductive health (Gifford et al. 2009: 16). The experiences and needs of sexually diverse youth, especially those who are newly arrived, are not well accounted for by current services and agencies (Noto et al. 2015). Young people's intergenerational relationships can add additional pressure (CMY 2014).

Although much research on youth and social cohesion emphasises risks and challenges, a focus on protective elements for the building and maintenance of social cohesion is also an emergent theme. Dandy and Pe-Pua (2013: v) identify core drivers for social cohesion as understanding of diversity, intercultural contact, community activities and social spaces, access to resources, mentoring and leadership development, and the promotion of the value of diversity at national and community levels. Related protective factors are outlined by Blades-Hamilton (2015), including opportunities for leadership and advocacy, network building and employment as significant enablers of social cohesion. Protective factors are often identified at the personal or psychosocial level, including such strengths as communication and problem-solving skills, healthy coping mechanisms, autonomy, positive self-concept and self-control, family support, connectedness and strong cultural identity (Mitchelson et al, 2010). 
Resilience, or the ability to cope and adapt positively in the face of adversity, is a commonly identified protective factor for youth and social cohesion. Cahill et al (2014: 5) describe youth resilience as:

'social competence, a sense of agency or responsibility, optimism, a sense of purpose or hope for the future, attachment to family, to school and to learning, problem-solving skills, effective coping style, pro-social values, a sense of self-efficacy, and positive self-regard.'

Some research has established personal strategies of resilience that are especially relevant to 'CALD' youth (see Vera et al., 2012; Neblett et al., 2016), with coping mechanisms such as 'fighting back' against racism, or adopting proactive strategies (characterised by feelings of agency, competence, ability to effect change before racism and other harms occur) connected to more positive internal feelings and stronger sense of belonging and integration (Walsh and TuvalMashiach, 2012: 69). Further, overcoming significant adversity has been shown to build resilience, with some research showing how refugee youth have special challenges but also bring particular resilience skills (Couch and Francis, 2006; Gifford, Correa-Velez, and Sampson, 2009: 16). Social support rather than just individual strategies is also identified as a strong predictor of coping and resilience. For example, religious involvement has been found to strengthen resilience in the face of discrimination and to support civic engagement and social cohesion (Butler-Barnes et al., 2016).

The youth and cohesion research we have overviewed here addresses questions of cohesion primarily through the paradigm of psychosocial protective/risk factors with particular attention to a 'CALD' cohort. Policy- and programme-oriented research tends to conceptualise matters of social cohesion as predominantly driven by individual and group behaviours, capacities and 
attitudes, with 'CALD' youth positioned as both at risk of a reduced sense of belonging, inclusion and social cohesion owing to a range of psychosocial factors, and as able to harness valuable protective factors, especially resilience, to enhance social cohesion. In addition to this psychosocial focus on what we might see as minoritized or racialized youth (see Harris, 2015; de Finney, 2011), this work is primarily concerned with young people's experiences 'in real life'. To date, little of this research has addressed young people's digital practices, even though ICTs and networked digital media shape new opportunities and challenges for social cohesion. Digital technologies are instead the focus of a separate set of studies on growing up in a digital age (Livingstone et al. 2011a), to which we turn next.

\section{Youth Wellbeing in a Digital World: A Socially Cohesive World Online?}

Youth engagement in digital practices has been a critically important area of scholarship and policy-focused research into wellbeing, inclusion and participation, and this also tends to be approached through a risk/protection framework. While social cohesion research has only minimally addressed young people's digital practices and digitally mediated experiences, we see a similar challenge that much research on youth and the digital takes insufficient account of cultural diversity and social cohesion. Cyber-safety and protection against online risks for an often undifferentiated 'mainstream' of youth shape the policy and research agenda (Office of the e-Safety Commissioner, 2019d). Much of this has been influenced by the ground-breaking $E U$ Kids Online project (see Livingstone et al. 2011a), which identifies and classifies the key online risks faced by youth as they seek engagement, connection and recognition through new media and the Internet. The most prevalent risks identified by this kind of cyber-safety research tend to be attributed to social and technological affordances that increase young people's exposure to content and practices that jeopardise safety and wellbeing. For example, they may be exposed to adult-oriented or violent content, be subjected to 'grooming' or sexual exploitation, or have their 
data misused (see Livingstone et al. 2011a: 13). This is not to say that there is no regard for diversity in cyber-safety scholarship, for example more recent additions to the cyber-safety resources offered by the Office of the e-Safety Commissioner have targeted the needs of LGBTIQ+ youth and also Aboriginal and Torres Strait Islander youth (see Office of the e-Safety Commissioner 2019a, 2019b and 2019c) but belonging to a non-Indigenous racial, ethnic or religious minority group has also been identified as a potential additional risk factor which increases instances of bullying and harassment, exposure to violence and hate speech. For example, EU Kids Online identifies ethnic minority groups and other 'discriminated against' groups as being more vulnerable to risks arising from online interactions than the general population, indicating that online risks are structured by 'offline' social contexts and inequalities (see also Hargittai and Hinnant 2008; Leurs 2014; Smith et al. 2012).

This is a landmark study in mapping cyber-safety challenges and protective factors for European youth, but this and other studies in this tradition provide fewer guidelines for identifying how a diversity of young people navigates risks to social cohesion online, or indeed, how socially cohesive digital environments can be created, sustained or threatened. While other research on online risk factors to social cohesion has identified cyber-racism, hate speech and violent extremism as some of the most significant challenges, not all of this research focuses specifically on youth (see Siapera et al. 2018). For example, a body of policy-focused Australian research has found growing evidence of impacts of cyber-racism on basic human rights and protections and the sense of belonging that participation in social media forums might otherwise encourage (AHRC 2011; Jakubowicz et al. 2017; Carlson and Fraser 2018). Dunn et al. (2012: 76) note that complaints of Internet-based racism and vilification are growing, and 'there are concerns that youth are particularly exposed to racism within social media spaces'. Caluya et al. (2018: 5) find that $20 \%$ of Australian 'CALD' youth has experienced harassment, discrimination or bullying online, and those who are politically active are more likely to report these experiences (see also 
Rice et al. 2016), but this is a fairly new area of research.

Alongside cyber-racism, hate speech, the growth of online hate groups and violent extremism emerge in the literature as factors that inhibit the formation of socially cohesive digital environments (Siapera et al. 2018: 3; see also Ekman 2015; van Zoonen et al. 2010; Varjas et al. 2013; Jakubowicz et al 2017). While there is still scant research on young people and hate speech, more exists on online violent extremism, which is often considered a precursor to terrorism, and a particular risk for youth. Some researchers note that while white pride and right-wing extremist groups and their online activities have a much longer history, anxieties around young people, digital media and social cohesion have focused on the online recruitment of vulnerable young people to join high profile global terrorist organisations such as ISIS (Vergani 2014; Talbot 2015), although it should be acknowledged that this imbalance is beginning to be addressed, with studies acknowledging and mapping the rise of white nationalist recruitment online (Daniels 2018) and the related role of platform affordances, algorithms and digital culture and vernacular in circulating and making mainstream white supremacist and other racialized and violent ideologies ( Noble 2018, Phillips 2015, Wooley \& Howard 2018).

Within the research literature on white violent extremism there is a particular emphasis on psychosocial factors that increase risks. For example, Hale (2012: 351), drawing on Lamberg (2001), argues that: 'adolescents who feel isolated and/or persecuted by classmates may be more easily swayed and/or feel empowered by joining such groups'. Such vulnerabilities are further exploited by 'common rhetorical strategies used by recruiters which identify the person recruited to the cause as an "underdog" or "victim" while the targeted group are demonised and symbolically constructed as an enemy and combatant' (Hale 2012: 351). Lennings, Amon, Brummert, and Lennings (2010:427) identify young people 'from backgrounds where parents may have been physically or psychologically absent', and/or where 'life skills and moral values 
were not a high priority', as being more vulnerable to extremist groups online for the sense of belonging, social and emotional connection they provide. This identification of personal loneliness and disconnection, and then manipulating these factors to create a sense that the online group can act as a kind of replacement 'family' is described as a form of 'subtle grooming' (Lennings et al 2010: 428).

These psychosocial factors, combined with digital affordances of anonymity (Phillips 2015), algorithmic biases and extremist groups' ability to game algorithms (Daniels 2018, Noble 2018), digital tools that enable users to create and disseminate content widely (Wooley \& Howard 2018), decentralized organization of networks and lack of legal regulation, and the way that platform specific affordances can amplify and normalise everyday racial discourses and signifiers (Matamoros-Fernandez 2017) are seen to shape risky environments online. For example, whilst extremist views are socially structured sentiments that exist in everyday cultures, the Internet is the place where text, audio and visual materials that promote violence can be widely disseminated. In particular, social network sites are seen to be used by fringe groups to communicate with and recruit members and channel users toward specific social media portals, 'effectively building communities of like-minded individuals' (Chau and Xu 2006: 350).

In addition to this field of research devoted to online risks to social cohesion, there is also a growing body of work that explores protective factors for young people. While racism and discrimination (and to a lesser extent attempted manipulation) can be common to online interactions and encounters (Leurs 2014: 261; see also Caluya et al. 2018; McIlwain 2017; van Zoonen et al. 2010; Ekman, 2015; Carlson and Frazer 2018), the benefits of staying connected online are seen to outweigh these risks for young people. It is now broadly recognised that digital media provide benefits and opportunities for young people to learn, form and sustain key relationships and connectedness, develop resilience, and participate in a growing digital economy. Consequently, 
concerns regarding online risks and their impacts on social cohesion have been met with initiatives that seek to encourage digital literacy and digital resilience, as these are identified as key protective factors.

'Digital literacy' refers to the technical and social skills to navigate technology, judge the quality and reliability of online information, and understand the social norms that apply in online settings (Third et al. 2014: 3, see also Gilhooly and Lee 2014). As Caluya et al (2018:11) note, an emphasis on digital skills, usage and competencies, treated as a 'literacy' issue, leads to an interest in pedagogical opportunities and the teaching of ICT skills and knowledge. A step beyond merely ensuring digital access, digital literacy is proposed as a set of teachable skills that can be imparted to vulnerable or minoritized groups to protect them from risk. A related key protective factor that builds on literacy is 'digital resilience': 'the ability to deal with negative experiences online or offline. Strategies focus on skilling users to adapt and respond effectively to potentially harmful online experiences' (Third et al. 2014: 7, see also Livingstone et al. 2011a, 2011b; Stald et al. 2014; Green et al. 2011).

Addressing the policy context, Third et al. (2014: 7) argue that whereas traditional cyber-safety research and interventions have focused on parental and school-based monitoring and intervention, or law enforcement strategies, the shift toward digital literacy and resilience 'emphasises a more strengths-based approach to cyber-safety, which focuses ... on intrinsic/internal protections'. While digital literacy education is largely organised around schoolbased programmes and initiatives, digital resilience is often targeted more specifically at the individual and family context. For example, in the EU Kids Online study, socially supportive environments at home and at school are seen as vital protective factors, and d'Haenens, Vandoninck, and Donoso (2013) consider peer support, teacher support and parent mediation as key to the development of digital resilience. Both literacy and resilience function as individual or 
group level strategies to reduce or manage risk, and 'CALD' groups are seen as particularly vulnerable and in need of additional support to develop these protective capacities.

We have demonstrated here that much policy- and programme-focussed research on cyber-safety and youth that attends to questions of social cohesion online tends to be framed around identification of risk/protective factors, and an individualising approach dominates. Next we outline a new direction that bridges social cohesion and cyber-safety agendas around the concept of citizenship. As Jones and Wallace (1992) have argued, citizenship is a valuable wholistic and processual concept that can draw together different frames of analysis in the sociology of youth (see Harris, 2015). Specifically, citizenship, in its more substantive sense, is a useful way to capture the socio-political processes by which young people can engage with and build diverse, safe and inclusive social spaces, and position themselves as rights-bearers and responsibilityholders. A focus on citizenship also directs attention to the spaces and practices of new civic cultures and publics that may be enabled by the global reach of young people's social media use and connections.

Here we utilise sociological models to encapsulate a 'thick' definition of citizenship as consisting of young people's rights, responsibilities, conditions and opportunities regarding political and civic participation, cultural identity, solidarity, recognition, belonging and 'the felt aspects of community membership' (Bosniak, 2000:479; see also Turner, 1997). We propose an approach that draws together work in the areas of digital and global citizenship to improve our understanding of youth, cultural diversity, social cohesion and the digital from this socio-political perspective. We suggest that centring citizenship enables the development of policy and programmes that address issues of participation, recognition and rights and not only psychosocial risks and protections. 
Within youth policy-oriented research, the concept of digital citizenship rather than literacy or resilience is becoming more prevalent. Digital citizenship refers less to individual attributes and technical skills than to social responsibilities to others online (see McCosker et al. 2016; Johns 2014, Johns and McCosker 2014; Third et al. 2014; van Zoonen et al. 2010; d'Haenans et al. 2007; Caluya et al. 2018). Digital citizenship is a step beyond digital literacy and resilience, whereby young people learn to not only navigate their own wellbeing online, but develop 'skills, knowledge, and values required to be an effective, ethical and safe user of ICT' (Third, et al. 2014). It also 'marks a shift to thinking about online practices as fundamentally social and community-based practices, as opposed to purely individual ones' (Third et al. 2014: 7). In extending notions of 'digital citizenship' even further, McCosker et al. (2016: 1-2) argue that, for youth, 'in the context of ubiquitous technology, the digital is now a part of, rather than apart from, citizenship and an implicit component of new claims to cultural rights, inclusion and participation'. A digital citizenship approach is thus interested in young people's political and civic capacity to build respectful online communities, promote digital inclusion and promote social cohesion, and in understanding 'how digital infrastructures can support a wider "civic culture", (Couldry et al, 2014:615).

Alongside the concept of digital citizenship in cyber-safety research, the idea of global citizenship has emerged as an important framework for understanding youth experience and opportunities in relation to social cohesion. Again, unlike the more psychosocial focus on risk and protective factors that promotes individual or group level support or interventions for enhancing resilience, a global citizenship approach focuses on ongoing social processes of social cohesion developed through cultivation of global civic responsibilities and ethics (Andreotti, 2006), and respectful and ethical negotiation of participation, engagement, claim-making and 
expression in shared spaces, from diverse local communities to global publics. Global citizenship approaches are concerned with how young people can and do make rights-claims as citizens of multiple and globally-connected spaces of obligation and belonging, how they are positioning themselves as members of global civil society, and how the interconnected and highly diverse spaces of the global, local and digital increasingly shape young people's opportunities for membership and participation in political and civic life (Harris, 2015; Wierenga \& Guevara, 2013).

Global citizenship policies and programmes identify that digital networks, technologies and cultures can enable forms of youth-led civic participation and social cohesion, intercultural understanding and learning (MCEETYA 2008, Wierenga \& Guevara 2013; UNESCO 2015), but this is underexplored in digital citizenship policies and programmes. In some cases, policymakers have attempted to address the 'global' dimension of digital citizenship by joining with media industry partners and human rights organisations to develop programmes that foster safe, responsible, equitable and inclusive citizenship of a digitally connected world (ACARA 2012; UNESCO 2015; Tan \& Park 2014). In Australia, these priorities have been well-established since the Melbourne Declaration on Educational Goals for Young Australians (MCEETYA 2008), which identifies that globalisation and technological change is "placing greater demands on education and skill development' particularly toward digital literacy and intercultural competencies to 'nurture a [...] sense of global citizenship' (MCEETYA 2008: 4-5).

Thus some productive global citizenship education focused on global civil responsibility is beginning to develop in conversation with the growth of young people's digital media use (UNESCO 2015; Cortesi et al. 2015; Culver and Kerr 2014), underlined by a belief that ICTs can promote global, cross-cultural interactions, and cosmopolitan skills and competencies (UNESCO 2015). Yet these initiatives are still under-developed. Further, fears regarding who is 
in control in a digital era and what role governments should play in managing young people's digital lives have led to a widening gap between policy framed around human rights and global citizenship and school-based programs still oriented toward risk management and social cohesion agendas (Livingstone et al 2011; Third et al 2014; Collin et al 2011; Office of the e-Safety Commissioner [online] n.d.).

In the interests of advancing these agendas that bring together questions of cohesion and the digital around the concept of global digital citizenship, we suggest that it is critical to consider not only opportunities that the digital enables to impart intercultural skills to youth, but to understand how young people's current digital practices and online 'communities of care' might already cultivate online cohesion and productive civic cultures. Digital interconnectedness has been found to increase young people's social capital, facilitating more diverse social networks that can transcend national boundaries and cultures, creating possibilities for increased intercultural engagement and respect for global diversity (Culver and Kerr 2014; Leurs and Ponzanesi 2011; Leurs 2015). Digital practices have been found to increase diaspora communities' political agency in addressing inequality and exclusion from traditional political participation and civic engagement, especially for youth (Harris and Roose 2014; Georgiou 2014; Caluya et al. 2018). The Internet and social media also provide unprecedented opportunities for members of dominant groups to engage in intercultural learning and anti-racist civic action (van Zoonen et al. 2010; Johns and McCosker 2014; McCosker and Johns 2014).

It is also established that alongside formal opportunities and initiatives, youth are commonly engaged in more mundane digital interactions arising from their face-to-face social networks and daily encounters with diverse groups in their neighbourhoods and schools (Leurs 2014; Leurs 2015) that can cultivate cosmopolitanism across all dimensions of their lives. 'Offline' social contexts continue to provide insight into young people's online negotiations of diversity; that is, 
those without diverse friendships and social connections offline are not necessarily going to broaden connections online, whereas youth in diverse neighbourhoods will most likely have heterogeneous online networks (Leurs, 2015). However, there is a continuous interplay amongst these domains that demonstrates the mutually reinforcing nature of a productive on- and offline ‘everyday multiculturalism' (Harris 2013), with incidental intercultural engagement in digital leisure and learning activities generating openness to diversity in local place. Digital and local interconnectedness can form a feedback loop in everyday experiences of diversity.

Simultaneous transnational and local connections enabled by digital media also help youth deepen civic networks and develop their intercultural capacities. Transnational connections can be problematized for producing intra-ethnic 'bonding' capital rather than what is often determined to be superior inter-ethnic 'bridging' capital (Putnam 2000). However, much empirical research challenges this assumption, showing that transnational and local connections are often entangled in ways that strengthen critical thinking, connection to global civil society and 'bridging' capital (Harris 2013). Transnational networks provide important forms of civic connection and continuity, while networks formed locally engender diverse encounters and cultural mixing. Both are positive and mutually reinforcing identity sources for youth, and one does not undermine the other (Leurs 2014).

Some media theorists have also highlighted the role of the Internet and digital media in lowering boundaries to youth participation in democratic processes (Coleman et al. 2005) and shaping more inclusive public spheres. There is debate about the extent to which young people's social media networks tend to be comprised of members of one's own cultural/ethnic group, perhaps softening the view that digital media creates greater cross-cultural connections and social capital (Leurs, 2014; Boyd, 2014). Social media architectures (i.e. algorithmic filtering) and automated accounts that manipulate social media publics (Wooley and Howard 2019; Benkler at al. 2018; Bucher 
2018) may also create polarisation and like-minded communities that promote ethnocentrism and essentialised rather than hybridised or cosmopolitan identities. However, the affordances of digital media have also widened and enabled youth inclusion and engagement in a range of civic and social networks. This may be particularly relevant to minoritized youth who face exclusion from other more formal mechanisms for civic and political expression. For example, Caluya et al. (2018: 4) have found that such 'young people are highly engaged in civic practices through digital technologies, participating across all key domains of citizenship: social, political, cultural and economic life'.

There are also important links between social and civic opportunities afforded by digital media. Social networking sites are identified as providing youth with resources and skills that facilitate 'educational outcomes; ...supportive relationships; identity formation; and ... a sense of belonging and self-esteem' (Collin et al. 2011: 7). The benefits of social networking sites 'are largely associated with the participatory nature of the contemporary digital environment' (Collin et al. 2011: 7), as they have been found to build a strong sense of social and community connectedness and belonging. Whilst the literature linking digital citizenship with civic engagement is predominantly focused on mainstream youth populations, there is some research that examines how minoritised youth use digital media to these ends. A growing body of research identifies digital, web-based technologies and SNSs as facilitating relationship-building, positive identity construction, increased digital literacy and civic and political participation through apps that enable group chat (Sun and Yu 2017). Such digital practices usually occur in non-institutional settings (home, leisure time), and are crucial activities that build civic engagement in the face of challenges of, for example, the resettlement process and/or experiences of marginalisation and discrimination (McCosker et al. 2016; Nakamura 2008). Everyday digital cultures and tools enable youth to 'express their multivocality and negotiate cultural differences' (Leurs and Ponzanesi 2011); with the very concepts of digital literacy reworked by these youth to include 
citizenship dimensions of cultural identity and intercultural communication (see Gilhooly and Lee 2014).

\section{$\underline{\text { Conclusion }}$}

Over the last decade, youth research on social cohesion and cultural diversity has become increasingly attentive to the everyday digital practices and cultures of young people, and the capacities of these forms of participation to address social harms, inequalities and injustices that threaten social cohesion. Simultaneously, debates about youth digital practices have become more engaged with issues of diversity and inclusion. However, policy agendas remain predominantly concerned with identifying online protective/risk factors to social cohesion via a psychosocial lens, and favouring digital literacy and resilience strategies as mechanisms for strengthening social cohesion amongst youth. As noted, much of the applied work in these areas has drawn on a risk and resilience frame, with interventions directed at 'CALD' youth. While we see value in exploring risk, protections and strengths-based approaches, we share with other scholars some concerns about the individualising, categorical and pathologising tendencies in these frameworks and some of their normative assumptions (Ungar 2008; Cahill et al. 2014; Shean 2015).

Here we have proposed a more sociological approach, utilising global digital citizenship as a frame which moves beyond these limiting ways of defining and addressing youth, digital practices and social cohesion. We have suggested that a global digital citizenship framework is a productive way to understand how youth are engaged in the shaping of civil spaces online, both through individual digital acts and practices which express and claim rights, and through collective practices, identifications, knowledge-sharing and forms of activism which contest inequalities and divisive social formations. In particular, we propose this framework as a necessary step beyond digital literacy and digital resilience approaches, which fail to recognise digital citizens as being 
differentially placed in broader, structural relations of power and which, therefore, can disregard barriers that racism, social division and polarisation pose to social cohesion. We see global digital citizenship as a way into addressing these imbalances, by considering the creative way citizens connected into global networks and circuits of obligation and care can challenge these inequalities.

\section{$\underline{\text { References }}$}

Andreotti, V. 2006, 'Soft versus Critical Global Citizenship Education', Policy and Practice: Development Education Review, 3 (Autumn): 40-51.

Australian Curriculum Assessment and Reporting Authority (ACARA), (2012) The Shape

of the Australian Curriculum. Sydney, N.S.W.

Australian Human Rights Commission (2011) 'Cyber Racism Fact Sheet' Australian

Human Rights Commission. https://www.humanrights.gov.au/publications/cyber-racismfact-sheet-2011.

Australian Bureau of Statistics (2017a) Census reveals a fast changing, culturally diverse nation. http://www.abs.gov.au/ausstats/abs@.nsf/lookup/Media\%20Release3.

Australian Bureau of Statistics (2017b) 3101.0 Australian Demographic Statistics, June 2017. http://www.abs.gov.au/ausstats/abs@.nsf/mf/3101.0

Banting, K., W. Kymlicka (2013) 'Is There Really a Retreat from Multiculturalism Policies? New Evidence from the Multiculturalism Policy Index', Comparative European Politics 11 (5): 577-598.

Benkler, Y., R. Faris, H. Roberts (2018) Network Propaganda: Manipulation, Disinformation, and Radicalisation in American Politics. New York: Oxford University Press.

Blades-Hamilton, E. (2015) Engaging our Youth: Our Future - A Report on the Victorian Multicultural Commission Forums for Young People 2014-2015. Melbourne: Research and Coordination Unit, Victorian Multicultural Commission. 
Bosniak, L. (2000) ‘Citizenship Denationalized’ 7 Indiana Journal of Global Legal Studies 447, 463-464.

Boyd, D. (2014) It's Complicated: The Social Lives of Networked Teens. New Yale: Yale University Press.

Bucher, T. (2018) If...Then: Algorithmic Power and Politics. New York: Oxford University Press.

Bulbeck, C. (2008) Sex, Love and Feminism in the Asia Pacific: A Cross Cultural Study of Young People's Attitudes. Milton Park: Routledge.

Butler-Barnes, S. T., Martin, P. P., Copeland-Linder, N., Seaton, E. K., Matusko, N., Caldwell, C. H., \& Jackson, J. S. (2016). The Protective Role of Religious Involvement in African American and Caribbean Black Adolescents' Experiences of Racial Discrimination. Youth \& Society, 1-29. Cahill, H., S. Beadle, A. Farrelly, R. Forster, K. Smith (2014) Building resilience in children and young people. Melbourne: Youth Research Centre, Melbourne Graduate School of Education, University of Melbourne.

G. Caluya, T. Bororica \& A. Yue (2018) Culturally and linguistically diverse young people and digital citizenship: A pilot study. Melbourne: Centre for Multicultural Youth

Carlson, B., Frazer, R. (2018) Social Media Mob: Being Indigenous Online. Sydney: Macquarie University.

Castles, S. (1999) 'Immigration and Social Cohesion', Growth 47: 35-46.

Chau, M., J. Xu (2006) 'A Framework for Locating and Analyzing Hate Groups in Blogs', Pacific Asia Conference on Information Systems (PACIS 2006), Kuala Lumpur.

CMY (2014) Negotiating Adolescence in Australia. Melbourne: Centre for Multicultural Youth. 
Coleman, S, C. Rowe (2011) Remixing citizenship: democracy and young people's use of the Internet. Dunfermline: Carnegie UK Trust/Carnegie YPI.

Collin, P, K. Karhilly, I. Richardson, A. Third (2011) The Benefits of Social Networking Services: A literature review. Melbourne: Cooperative Research Centre for Young People, Technology and Wellbeing.

Colucci, E., Szwarc, J., Minas, H., Paxton, G., Guerra, C. (2014) 'The utilisation of mental health services by children and young people from a refugee background: a systematic literature review', International Journal of Culture and Mental Health 7(1): 86-108.

Cortesi, S., U. Gasser (eds) (2015) 'Digitally connected: Global perspectives on youth and digital media' in S. Cortesi and U. Gasser. Remixing citizenship: democracy and young people's use of the Internet. Cambridge: The Berkman Center for Internet \& Society at Harvard University.

Couch, J., \& Francis, S. (2006). Participation for all? Searching for marginalized voices: the case for including refugeeyoung people. Children, YouthandEnvironments 16, 272-290.

Couldry, N. Stephansen, H. Fotopoulou, A. MacDonald, R. Clark, W \& Luke Dickens (2014) Digital citizenship? Narrative Exchange and the Changing Terms of Civic Culture, Citizenship Studies, 18(6-7): 615-629.

Cuervo, H., \& Miranda, A. (2019) Youth, Inequality and Social Change in the Global South. Singpore: Springer.

Culver, S.H., P.A. Kerr (2014) Global Citizenship in a Digital World. UNITWIN Cooperation on Media and Information Literacy and Intercultural Dialogue, and International Clearinghouse on Children, Youth and Media at NORDICOM.

Dandy, J., R. Pe-Pua (2013) Research into the Current and Emerging Drivers for Social Cohesion, Social Division and Conflict in Multicultural Australia. Perth and Sydney: Edith Cowan University and The University of New South Wales.

Daniels, J. (2018). The Algorithmic Rise of the "Alt-Right." Contexts, 17(1), 60-65. 
Delanty, G (2010) Community. London: Routledge.

d'Haenens, L., J. Koeman, and F. Saeys (2007) 'Digital citizenship among ethnic minority youths in the Netherlands and Flanders', New Media \& Society 9(2): 278-299.

Dunn, K., H. Babacan, J. Forrest, Y. Paradies, A. Pedersen, J. Nelson (2012) ‘Submission to the National Anti-Racism Partnership \& Strategy Discussion Paper' https://itstopswithme.humanrights.gov.au/sites/default/files/iswmsubmissions/Sub082.Challenging\%20Racism\%20project.doc. Ekman, M. (2015) 'Online Islamophobia and the politics of fear: manufacturing the green scare', Ethnic and Racial Studies 38(11): 1986-2002.

Francis, S., \& Cornfoot, S. (2007). Multicultural Youth in Australia: Settlement and Transition. Melbourne: Centre for Multicultural Youth Issues.

Georgiou, M (2014) 'Diaspora in the digital era: minorities and media representations', Journal on Ethnopolitics and Minority Issues in Europe, 12(4): 80-99.

Gifford, S., I. Correa-Velez, R. Sampson (2009) Good starts for recently arrived youth with refugee backgrounds: promoting wellbeing in the first three years of settlement in Melbourne, Australia. Melbourne: La Trobe Refugee Research Centre, La Trobe University and the Victorian Foundation for Survivors of Torture (Foundation House).

Gilhooly, D., E. Lee (2014) 'The Role of Digital Literacy Practices on Refugee Resettlement: The Case of Three Karen Brothers', Journal of Adolescent \& Adult Literacy 57(5): 387-396. Green, L., D. Brady, K. Olafsson, J.Hartley, C. Lumby 2011) Risks and safety for Australian children on the internet: Full findings from the AU Kids Online survey of 9-16 years olds and their parents. Kelvin Grove: Queensland ARC Centre for Excellence for Creative Industries and Innovation.

Hale, W.C. (2012) 'Extremism on the World Wide Web: a research review', Criminal Justice Studies 25(4): 343-356. 
Hargittai, E., A. Hinnant (2008) 'Digital Inequality: Differences in Young Adults' Use of the Internet.' Communication Research 35(5): 602-621.

Harris, A. (2013) Young People and Everyday Multiculturalism. New York and London: Routledge.

Harris, A. (2015) ‘DIY Citizenship: Participation, Belonging \& Youth Cultural Practices' Youth Cultures, Belonging and Transitions D. Woodman \& A. Bennett (eds), Palgrave, Basingstoke. Harris, A., J. Roose (2014) 'DIY Citizenship amongst young Muslims: experiences of the “ordinary”.' Journal of Youth Studies 17(6): 794-813.

Hugo, G., K. McDougall, G. Tan, an H. Feist (2014) The CALD Youth Census Report 2014. Carlton: The Multicultural Youth Advocacy Network (MYAN) Australia.

Jakubowicz, A., K. Dunn, G. Mason, Y. Paradies, A.-M. Bliuc, N. Bahfen, , A. Oboler, R. Atie, K. Connelly (2017) Cyber Racism and Community Resilience. London: Palgrave.

Johns, A. (2014) 'Muslim Young People Online: “Acts of Citizenship" in Socially Networked Spaces', Social Inclusion 2(2): 1-12.

Johns, A., A. McCosker (2014) 'Social media conflict: platforms for racial vilification, or acts of provocation and citizenship?' Communication, Politics \& Culture 47(3): 44-54. Jones G \& Wallace C (1992) Youth, Family and Citizenship, Buckingham: Open University Press.

Lennings, C.J., K.L. Amon, H. Brummert, N.J. Lennings (2010) 'Grooming for Terror: The Internet and Young People', Psychiatry, Psychology \& Law 17(3): 424-437.

Leurs, K. 2014. 'Digital throwntogetherness: Young Londoners Negotiating Urban Politics of Difference and Encounters on Facebook', Popular Communication: The International Journal of Media and Culture 12(4): 251-265.

Leurs, K. (2015). Digital passages: migrant youth 2.0: diaspora, gender and youth cultural intersections. Amsterdam: Amsterdam University Press. 
Leurs, K, and S. Ponzanesi (2011) 'Mediated crossroads: youthful digital diasporas', M/C - A Journal of Media and Culture 14 (2). http://journal.media-

culture.org.au/index.php/mcjournal/article/view/324

Liddy, N. (2011) 'Strengthening Belonging and Identity: The People of Australia, Multiculturalism and CALD Young People.' Australian Mosaic 28: 6-8.

Livingstone, S., L. Haddon, A. Gorzig, K. Olafsson (2011a) Risks and safety on the internet: The perspective of European Children. Full Findings. London: EU Kids Online.

Livingstone, S, L. Haddon, A. Gorzig, and K. Olafsson (2011b) EU Kids Online Final Report. London: EU Kids Online.

Mansouri, F., Kamp, A. (2007) 'Structural deficiency or cultural racism: the educational and social experiences of Arab-Australian Youth', Australian Journal of Social Issues 42(1): 17-30. Markus, A. (2015) Mapping Social Cohesion: The Scanlon Foundation surveys 2015. Melbourne: ACJC, Faculty of Arts, Monash University

Markus, A.B., L. Kirpitchenko (2007) ‘Conceptualising social cohesion’, pp. 21-32 in J. Jupp, J. Nieuwenhuysen, E Dawson (eds), Social Cohesion in Australia. 1st edition. Melbourne: Cambridge University Press.

Matamoros-Fernández, A. (2017). Platformed racism: the mediation and circulation of an Australian race-based controversy on Twitter, Facebook and YouTube. Information, Communication \& Society, 20(6), 930-946.

McCosker, A, and A. Johns (2014) 'Contested publics: racist rants, bystander action and social media acts of citizenship', Media International Australia 151: 66-72.

McCosker, A, S. Vivienne, and A. Johns (2016) Negotiating Digital Citizenship: Control, Contest and Culture. Lanham: Rowman \& Littlefield International.

McIlwain, C. (2017) 'Racial formation, inequality and the political economy of web traffic' Information, Communication \& Society 20(7): 1073-1089. 
McMichael C., C. Nunn, S.M. Gifford, I. Correa-Velez (2015) 'Studying Refugee Settlement through Longitudinal Research: Methodological and Ethical Insights from the Good Starts Study', Journal of Refugee Studies 28(2): 238-257.

Ministerial Council on Education, Employment, Training, and Youth Affairs (2008) Melbourne Declaration on Educational Goals for Young Australians. Melbourne: MCEETYA.

Mission Australia, Black Dog Institute (2015) Young people's mental health over the years: Youth Survey 2012-14. Sydney: Mission Australia.

Mitchelson, M.R., H.E. Erskine, E. Ramirez, F. Suleman, R. Prasad-Ildes, D.Siskind, M. Harris (2010) 'BRiTA Futures: A resilience-building program for children and young people from culturally and linguistically diverse backgrounds - program description and preliminary findings', Advances in Mental Health 9(3): 242-254.

Nakamura, L. (2008) Digitizing Race: Visual Cultures of the Internet. Minnesota and London: University of Minnesota Press.

Neblett,E. W., Jr., Sosoo,E.E., Willis, H. A., Bernard, D.L., Bae,J., \& Billingsley, J.T. (2016). Racism, Racial Resilience, and African American Youth Development: Person-Centered Analysis as a Tool to PromoteEquityandJustice.Advancesin Child Development and Behavior, 51, $43-79$.

Noble, S. (2018). Algorithms of oppression: how search engines reinforce racism . New York: New York University Press.

Noto, O., W. Leonard, A. Mitchell (2015) ‘Nothing for them’: Understanding the support needs of LGBT young people from refugee and newly arrive backgrounds. Melbourne: The Australian Research Centre in Sex, Health \& Society, La Trobe University

Office of the eSafety Commissioner n.d.[Online, 2019a] Digital Citizenship. Canberra: Australian Government. Available from https://www.esafety.gov.au/education$\underline{\text { resources/classroom-resources/digital-citizenship. }}$

Office of the e-Safety Commissioner n.d [online, 2019b] Lesbian, Gay, Bi, Trans and/or Intersex People: Online safety advice and support for the LGBTQI community. Canberra: Australian 
Government. Available from: https://www.esafety.gov.au/key-issues/tailored-advice/lesbiangay-bi-trans-queer-intersex

Office of the e-Safety Commissioner n.d. [online, 2019c] Aboriginal and Torres Strait Islander Peoples: Resources to Help Keep Our Mob Safe Online. Canberra: Australian Government. Available from:https://www.esafety.gov.au/key-issues/tailored-advice/aboriginal-and-torres$\underline{\text { strait-islander-peoples }}$

Office of the e-Safety Commissioner n.d. [online, 2019d] Young People and Social Cohesion. Canberra: Australian Government. Available from: https://www.esafety.gov.au/about$\underline{\text { us/research/young-people-social-cohesion }}$

Putnam, R.D. (2000) Bowling Alone: The Collapse and Revival of American Community. New York: Simon \& Schuster.

Phillips, W. (2015). This is why we can't have nice things : mapping the relationship between online trolling and mainstream culture. Cambridge, Massachusetts: The MIT Press.

Rice, E., E. Haynes, P. Royce, S. Thompson (2016) 'Social media and digital technology use among Indigenous young people in Australia: a literature review', International Journal for Equity in Health 15: 1-16.

Shean, M. (2015) Current theories relating to resilience and young people: A literature review. Melbourne: Victorian Health Promotion Foundation.

Siapera, E., E. Moreo, J. Zhou (2018) Hate Track: Tracking and Monitoring Racist Hate Speech Online. DCU School of Communications, Institute for Future Media and Journalism, AntiBullying Centre, and Insight Centre for Computer Analytics, School of Computing, Dublin. Smith, J., Z. Skrbis, M. Western (2012) 'Beneath the "Digital Native" myth', Journal of Sociology 49(1): 91-118.

Stald, G., L. Green, M. Barbovski, L. Haddon, G. Mascheroni, B. Sagvari, B. Scifo, L. Tsaliki (2014) Online on the mobile: Internet use on smartphones and associated risks amoung youth in Europe. London: EU Kids Online. 
Sun, W., H. Yu (2017) 'Digital/Social Media and the Chinese Community in Australia', Media Asia 43(3-4): 165-168.

Talbot, D. (2015) 'Fighting ISIS Online', MIT Technology Review 118 (6).

Tan, M.M. \& Park, J. (2015) Fostering Digital Citizenship through Safe and Responsible Use of ICT. Bangkok, Thailand: Asia and Pacific Regional Bureau for Education.

Third, A., P. Forrest-Lawrence, A. Collier (2014) The Cyber Safety Challenge: from risk to resilience. Sydney: University of Western Sydney.

Turner, B. (1997) Citizenship studies: A general theory, Citizenship Studies, 1:1, 5-18

UNESCO (2015) Empowering Youth to Build Peace. Paris: United Nations Educational, Scientific and Cultural Organization.

Ungar, M. (2008) 'Resilience across Cultures', British Journal of Social Work 38(2): 218-235. van Zoonen, L., F. Vis, S. Mihelj (2010) 'Performing Citizenship on YouTube: activism, satire and online debate around the anti-Islam video Fitna', Critical Discourse Studies 7(4): 249-262. Varjas, K., J. Meyers, S. Kiperman, A. Howard (2013) 'Technology Hurts? Lesbian, Gay, and Bisexual Youth Perspectives of Technology and Cyberbullying', Journal of School Violence 12(1): 27-44.

Vera, E. M., Vacek, K., Blackmon, S. k., Coyle, L., Gomez, K., Jorgenson, K., .. Steele, J. C. (2012).

Subjective Well-Being in Urban, Ethnically Diverse Adolescents The Role of Stress and Coping. Youth \& Society, 44(3), 331-347.

Vergani, M. (2014) 'Neo-Jihadist Prosumers and Al Qaeda Single Narrative: The Case Study of Giuliano Delnevo', Studies in Conflict \& Terrorism 37(7): 604-617.

VicHealth, CSIRO (2015) Bright Futures: Megatrends impacting the mental wellbeing of young Victorians over the coming 20 years. Melbourne: Victorian Health Promotion Foundation.

Walsh, S. D., \& Tuval-Mashiach, R. (2012). Ethiopian Emerging Adult Immigrants in Israel:Coping With Discrimination andRacism. Youth \& Society, 44(1),49-75. 
Wierenga, A., Wyn, J., Guevara, J. R., Gough, A., Schultz, L., Beadle, S., . . King, J. (2008). Youth-led learning: Local connections \& global citizenship. Melbourne: Research Report 31, Australian Youth Research Centre, RMIT University.

Wooley, S.C., P.N. Howard (2019) Computational propaganda: Political Parties, Politicians and Political Manipulation on Social Media. New York: Oxford University Press. 